a treatment plan proposed by the treating psychiatrist. This plan has to detail the treatment modalities (day hospital and other out-patient treatments), their frequency and their type. This treatment plan has to be written in reasonable detail but it does not include commitments that are unduly burdensome to the patient's treatment team. However, the use of force to give medication is not permitted in community clinics or other community settings. The treatment plan has to be modified each time a substantial change is implemented in the patient's treatment. It has to be elaborated by the psychiatrist at the hospital in which the patient has been hospitalised at the first stage of treatment.

\section{Conclusion}

The law of 27 September 2013 represents a new step in psychiatric involuntary treatment in France. One of its main characteristics is to introduce the Judge for Liberties and Detention in the control of treatment without the patient's consent, shifting to judicial power what was previously an administrative power (Senon \& Voyer, 2012). Indeed, it gives to the judge the task of checking if the limitations on individual liberties imposed by the psychiatric involuntary treatment are well adapted to and commensurate with the patient's therapeutic needs. Decisions of the French Constitutional Council allow the French mental health law to comply with the European recommendations.

\section{References}

Senon, J. L. \& Voyer, M. (2012) Modalités et impact de la mise en oeuvre de la loi du 5 juillet 2011: de l'impérieuse nécessité de placer le patient au centre de nos préoccupations. Annales Médicopsychologiques, 170, 693-698.

Senon, J. L., Jonas, C. \& Voyer, M. (2012a) Les soins sous contrainte des malades mentaux depuis la loi du 5 juillet 2011 'relative aux droits et à la protection des personnes faisant l'objet de soins psychiatriques et aux modalités de leur prise en charge'. Annales Médico-psychologiques, 170, 211-221.

Senon J. L., Leturmy, L. \& Voyer, M. (2012b) Les soins sous contrainte des malades mentaux. In Psychocriminologie (eds J. L. Senon, G. Lopez \& R. Cario), pp. 295-308. Dunod.

\section{MENTAL HEALTHLAW PROFILE}

\title{
Mental health law profile on the Republic of Ireland
}

\author{
Anna Datta ${ }^{1}$ and Justin Frewen ${ }^{2}$
}

${ }^{1}$ GP Rural Track Training Scheme, Gilbert Bain Hospital, Lerwick, Shetland Islands, UK, email anna828359@yahoo.com ${ }^{2}$ United Nations Consultant
This article provides a brief overview of the legislation that has been enacted in Ireland with respect to mental health, in particular the 2001 Mental Health Act. Although that Act was a positive step towards developing an Irish mental health service that protects the human rights of service users, a number of concerns remain, including issues related to consent and capacity, involuntary out-patient treatment and admission, the adversarial nature and timing of tribunals, and the lack of safeguards for voluntary patients.

\section{Background}

The Mental Treatment Act (MTA) was introduced in the Republic of Ireland in 1945 in response to strong public and professional pressure for mental health service reform and the introduction of involuntary admission procedures similar to those introduced in 1930 and 1932 in the UK and Northern Ireland, respectively (Kelly, 2008, pp. 65-66). The MTA introduced two new procedures for involuntary detention. The first stipulated that the patient must be examined by an authorised medical officer within 24 hours of an application for committal. Should the patient's need for involuntary committal be corroborated, he or she had to be examined by the district mental hospital's medical officer to confirm this. Detention would be for an indefinite period. The second procedure introduced was related to a new category of patient - the temporary patient - who could be detained for up to 6 months (Kelly, 2008, p. 66).

The MTA also introduced the concept of out-patient care for non-serious mental illness, a measure which it was hoped would reduce stigma, at least to some extent, with respect to mental ill health and district mental hospitals (Kelly, 2008, p. 67). It was amended by eight subsequent pieces of legislation up to and including the Health Act 1970.

\section{The 2001 Mental Health Act}

As the 20th century drew to a close, with growing recognition of the human rights of people with mental illness, pressure grew for new legislation (Nwachukwu et al, 2010, pp. 436-437). In July 2001, a Mental Health Act (MHA), regulating both adult and child psychiatry, was passed by the 
Irish parliament. It became fully implemented in a phased manner from 1 November 2006 (Kelly, 2007 , p. 21). Since then, several pieces of supporting legislation have been enacted, such as the 2004 and 2007 Health Acts, and the 2005 Disability Act. Also, 2006 and 2010 Criminal Law (Insanity) Acts and legislation on wards of court and the power of enduring attorney have significantly affected implementation of the MHA.

\section{Involuntary detention}

The primary objective of the 2001 MHA was to reform the process of involuntary detention and to provide protection for involuntarily detained patients (Kelly, 2007, p. 21). It removed 'indefinite duration' detention orders and stipulated new procedures for involuntary admission, including automatic, independent reviews of detention orders by tribunals, and the provision of free legal representation and independent psychiatric opinions for detained patients (Kelly, 2011, p. 440). It also provided a clear definition of a 'child' and the criteria of mental disorder.

For an individual to be admitted involuntarily under the MHA:

- an application must be made by a spouse, relative, member of the Irish police force, authorised officer or another person

- a registered medical practitioner must provide a recommendation within 24 hours of receiving the application

- an admission order must be compiled by a consultant psychiatrist working in an approved centre, once she or he has confirmed that the individual has a mental disorder (Kelly, 2007, pp. 21-22).

The legislation does allow for involuntary admission to an 'approved' centre, under certain clearly prescribed circumstances (Kelly, 2007, p. 21). A detained patient can, however, be permitted to leave, subject to such conditions as the consultant psychiatrist considers appropriate, and can still access mental health tribunals.

Since the introduction of the MHA, there has been a reduction in involuntary admissions, from 2830 in 2005 to 2132 in 2013. In total, 332 children were admitted involuntarily, of whom $22.3 \%$ went to an adult unit, which, although still a significant number, represents a reduction on previous figures (Department of Health and Children, 2007, p. 9; Mental Health Commission, 2013, pp. 32, 40).

\section{Mental Health Commission}

The MHA aimed to improve existing and institute new structures for ensuring the quality of mental healthcare standards, and the Mental Health Commission (MHC) was established to advance this objective (Mhaoláin \& Kelly, 2009, p. 161).

The MHC's principal objectives are to promote high standards and good practice in mental health service delivery and to take all reasonable steps to protect the interests of persons detained in approved centres under the Act. With respect to involuntary detention, the MHC:

- appoints mental health tribunals and tribunal members to automatically review admission of every involuntary patient

- establishes a panel of consultant psychiatrists to implement independent medical examinations of persons involuntarily admitted to approved centres

- organises a legal aid scheme for involuntarily admitted persons

- maintains a register of approved centres and advises the Minister for Health and Children on a range of issues, including standards in approved centres

- prepares and periodically reviews codes of practice to provide guidance for persons working in mental health services (Mental Health Commission, 2005, section 1.5).

The MHC appoints an Inspector of Mental Health Services, whose duties include inspecting all approved centres at least once yearly, preparing an annual review of mental health services and reporting to the $\mathrm{MCH}$ on the quality of mental healthcare, treatment received by service users and other service aspects (Mental Health Commission, 2005, section 1.6). However, the Inspectorate has tended to pay less attention to the monitoring of community-based services in terms of their quality and operations.

\section{Capacity and consent}

The patient's consent to be treated is required in all circumstances except when an admission order is made by a consultant psychiatrist.

However, the MHA has been criticised for failing to deal adequately with certain situations, such as where an individual lacks the capacity to agree to voluntary admission but does not fulfil the conditions required for involuntary admission or when a voluntary patient refuses to leave the approved centre or receive appropriate treatment (Mhaoláin \& Kelly, 2009, p. 162). Moreover, the MHA does not require informed consent from voluntary patients or insist they possess the capacity to make an informed judgement and also provides inadequate guidance should they require assistance or advocacy support.

The Irish Law Reform Commission and Amnesty International, among others, have recommended the urgent introduction of capacity legislation that takes into account not only the MHA but also the 2006 Criminal Law (Insanity) Act (Amnesty International, 2010). Although an Assisted Decision-Making (Capacity) Bill was finally published in 2013, work on it is still ongoing.

\section{Discussion}

First, it should be acknowledged that the MHA 2001 was a positive step towards developing an Irish mental health service that protects the 
human rights of service users, both voluntary and involuntary. Nevertheless, a number of concerns remain.

The MHA fails to address involuntary outpatient treatment and involuntary admission for assessment, neither of which is permitted. Although provision is made for involuntary community treatment where the detained individual may be given leave - subject to adhering to the consultant psychiatrist's conditions - and has the right to a review tribunal, it is insufficiently detailed.

Concern has also been expressed by psychiatrists with respect to the adversarial nature and timing of tribunals, which may take place as the patient is about to be discharged, and their potential for disrupting normal clinical activities, which can all impact negatively on the therapeutic relationship (Jabbar et al, 2011, p. 293).

The European Committee for the Prevention of Torture (2011, pp. 60,63) highlighted the lack of safeguards for voluntary patients, the need to amend the Act with respect to the application of electroconvulsive therapy and the absence of an independent capacity assessment.

Finally, neither the MHA nor subsequent legislation, such as the Health Act 2004, provides a legislative framework for planning or covers all elements of the provision of mental health services, such as the delivery of community mental health services or accountability for mental health expenditure (Amnesty International, 2010, p. 55).

\section{References}

Amnesty International (2010) Legislating for Change: Accountability and Reform of Our Mental Health Services. Existing Law in Ireland. Available at http://www.amnesty.ie/sites/default/files/Legislating \% 20 for \% 20Change.pdf (accessed December 2015).

Department of Health and Children (2007) Review of the Operation of the Mental Health Act 2001: Findings and Conclusions. Department of Health and Children.

European Committee for the Prevention of Torture (2011) Report to the Government of Ireland on the Visit to Ireland Carried Out by the European Committee for the Prevention of Torture and Inhuman or Degrading Treatment or Punishment (CPT). Available at http:// www.cpt.coe.int/documents/irl/2011-03-inf-eng.pdf (accessed December 2015).

Jabbar, F., Kelly, B. D. \& Casey, P. (2011) National survey of psychiatrists' responses to implementation of the Mental Health Act 2001 in Ireland. Irish Journal of Medical Sciences, 179, 291-294.

Kelly, B. D. (2007) The Irish Mental Health Act 2001. Psychiatric Bulletin, 31, 21-24

Kelly, B. D. (2008) Mental health law in Ireland, 1945 to 2001 reformation and renewal. Medico-Legal Journal, 76, 65-72.

Kelly, B. D. (2011) Mental health legislation and human rights in England, Wales and the Republic of Ireland. International Journal of Law and Psychiatry, 34, 439-454.

Mental Health Commission (2005) Reference Guide Mental Health Act 2001. Available at http://www.mhcirl.ie/Mental_Health Act_2001/Reference_Guide_to_the_Mental_Health_Act_2001/ (accessed December 2015)

Mental Health Commission (2013) Annual Report 2013. Available at http://www.mhcirl.ie/File/ar2013.pdf (accessed December 2015).

Mhaoláin, Á. N. \& Kelly, B. D. (2009) The Irish Mental Health Act 2001: where are we now? Psychiatric Bulletin, 33, 161-164.

Nwachukwu, I., Crumlish N., Heron, E. A., et al (2010) Irish Mental Health Act 2001: impact on involuntary admissions in a community mental health service in Dublin. The Psychiatrist, 34, 436-440.

\title{
MENTAL HEALTHLAW \\ Compulsory admission and involuntary treatment in Portugal
}

\author{
Telma Almeida ${ }^{1}$ and Andrew Molodynski
}

'Resident in Psychiatry, Department of Psychiatry and Mental Health, Vila Nova de Gaia/Espinho Hospital, Portugal, email telmafilipalmeida@gmai. com

${ }^{2}$ Consultant Psychiatrist, Oxford Health NHS Foundation Trust: Honorary Senior Clinical Lecturer, Oxford University, UK
This paper details the grounds for compulsory treatment, compulsory admissions in an emergency department and compulsory outpatient treatment in Portugal. Portuguese mental health legislation has improved significantly over recent years, with enhanced safeguards, rapid and rigorous review and clear criteria for compulsory treatment, although much remains to be done, especially in relation to the 'move into the community'.

Portugal is a country in south-western Europe with a total area of $92345 \mathrm{~km}^{2}$ and a population of around 10.5 million people. There are 6.14 psychiatrists per 100000 population (World Health Organization, 2011).
The first Mental Health Act in Portugal was adopted in 1963. At around that time the need to integrate mental health services with the general healthcare system was becoming increasingly clear. National mental health programmes in 1985 and 1989 included important measures to integrate mental healthcare in general hospitals and to develop community mental health. In 1992 legislation stipulated the integration of all mental health centres into general hospitals. However, the development of community mental health services initiated in the 1980s was interrupted in the early 1990 s, for political reasons. The need to review the mental health law in Portugal and consequently the way mental health services were organised became increasingly urgent with the recommendations from the United Nations and the World 